\title{
Dn $1651-9$
}

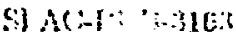

Inis $\mathrm{iss}$

BARYON-ANTIBARYON ANGULAR CORREIATONE

(iv) (wWF- $\$ 3068 \%-2$ IN QUARK JETS*

\author{
ALFRED BARTL ${ }^{\dagger}$ \\ Stanford Linear Accelerator Center \\ Stanjord Universily, Stanjord, Catifornia 9.4:05
}

SLIC-PUi:- -3163

$0 E 83 \quad 015023$

\begin{abstract}
The azimuthal angular distribution of baryon-ankjbnryon pairs in a quark jet is calculated and compared with experimental data in $e^{+} e^{-}$annihilicioo.
\end{abstract}

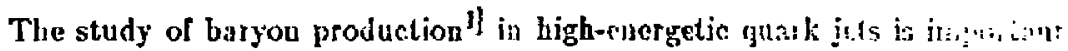
because it gives more insight jnto the mechanism of quark hadrona: asori. "in:"

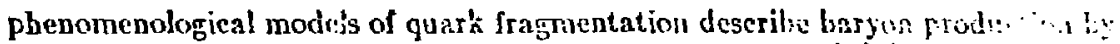

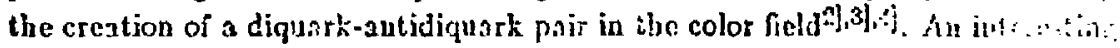

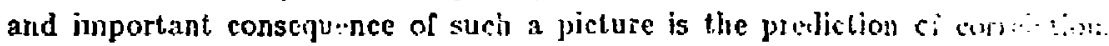

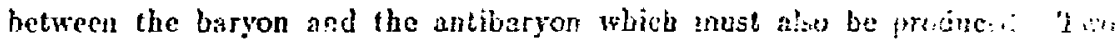

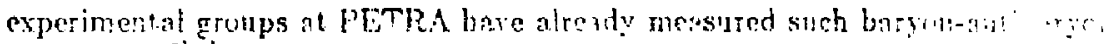

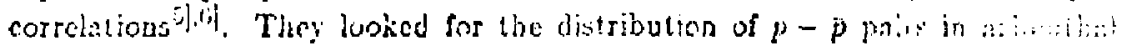

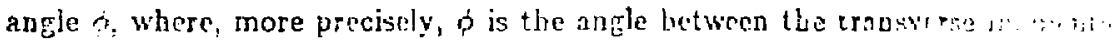

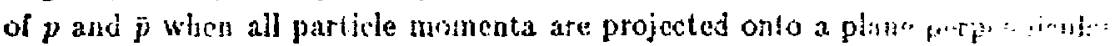

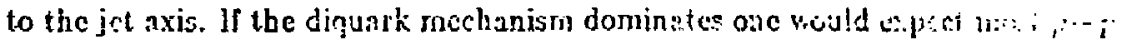
pajs be near $\dot{\varphi}==180^{\circ}$.

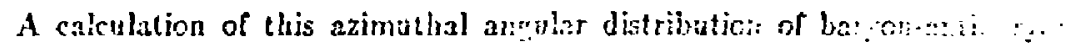

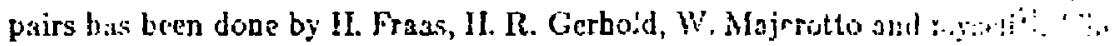
besic a

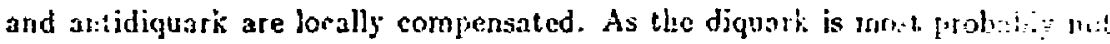

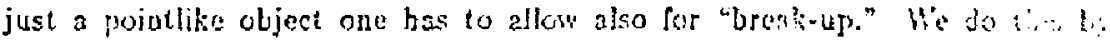
assigning a probability $m_{3}$ that the first particle ernitted from sthe diquat $\vdots$ a

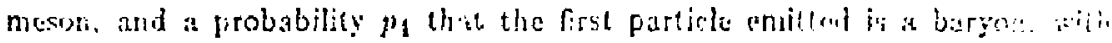

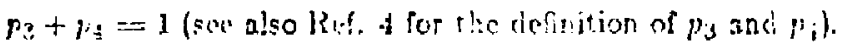

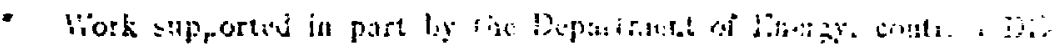

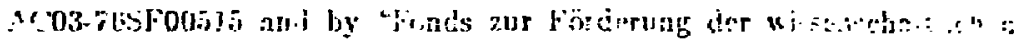

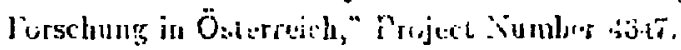

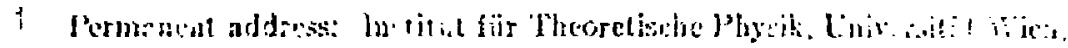

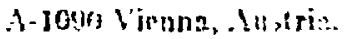

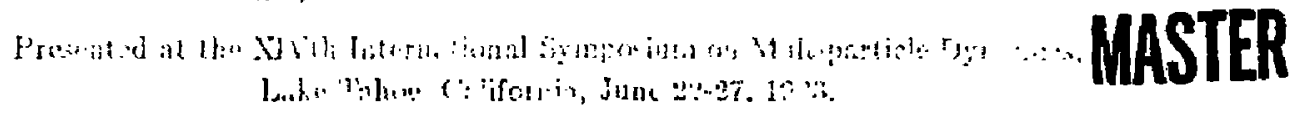




\section{DISCLAIMER}

This repon was prepared as an eccount of work sponsored by an agency of the United State Government. Neither the United States Government nor any agency thereof. nor any of their employees, makes any warranty, express or implied, or essumes eay kgal lisbility or responajbility for the accurncy, completenesh or usefulaess of any information, apparatus, produch or process disclosed, or represents that its use would oot infringe privately owned rigbta. Reference hercin to any spocinic commercial product, procese, or service by irade uame, trademark, munufacturer, or otherwise dos not necessarily constitute or imply its endortement, recommendution, of favoring by the United States Governmenl or any agency thereof. The views and opinions of authoes expressed herain do not necessurily state of meffect those of the Uniled Stales Gowernment or any agency thereof. 


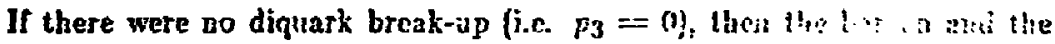

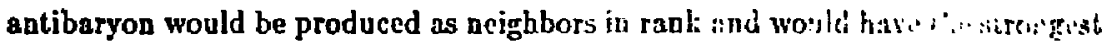

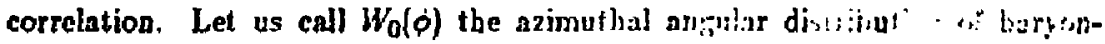

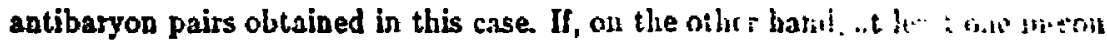

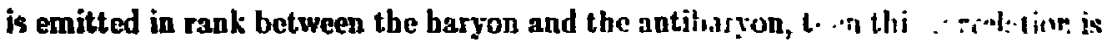

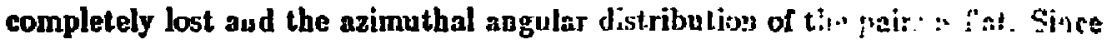
the first case occurs with probability $p_{4}=1-p_{3}$, i.l geat $r: !$ we $\because \therefore$ in ist the baryon-antibaryon angular distribution

$$
W(\phi)=\left(1-p_{3}\right) W_{0}(\phi)+p_{3} \frac{1}{2 \pi}
$$

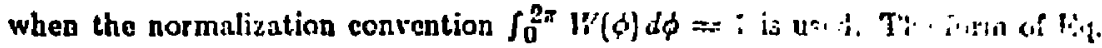
(1) remains valid even if the baryon and the antibaryon a: ave: ; rovivets of

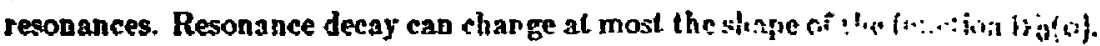

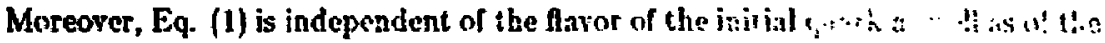

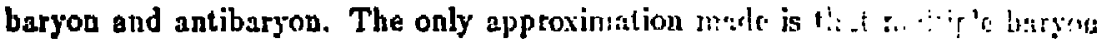

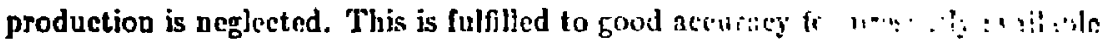
energies.

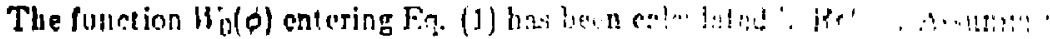

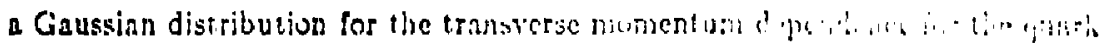

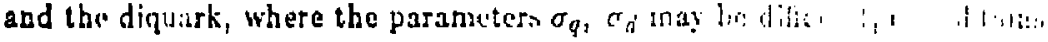

$$
W_{0}(\phi)=\frac{\alpha(\alpha+2)}{2 \pi(\alpha+1)^{2}} \sum_{n=0}^{\infty} \frac{[(1 n+1)]^{n}}{n !}\left(\begin{array}{c}
2 n \\
n+i
\end{array}\right)
$$

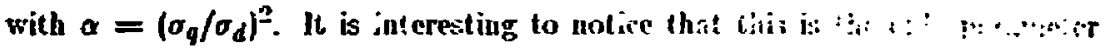

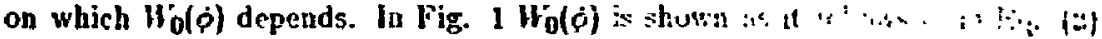

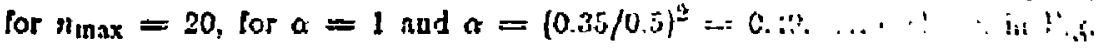
1 is $H_{0}(\phi)$ jesulting from a Monte Carlo calcularion in 1 .

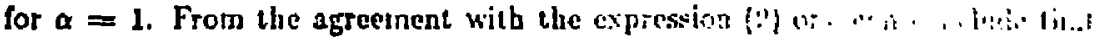

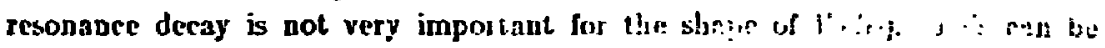

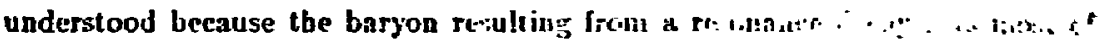
lie inomentum.

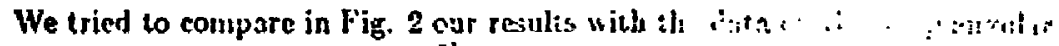

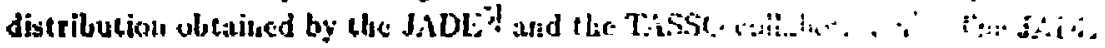

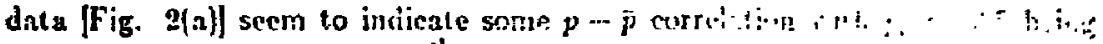

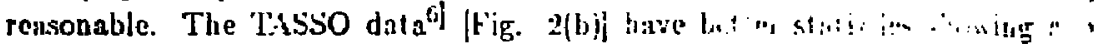

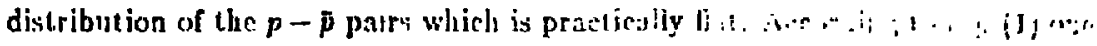




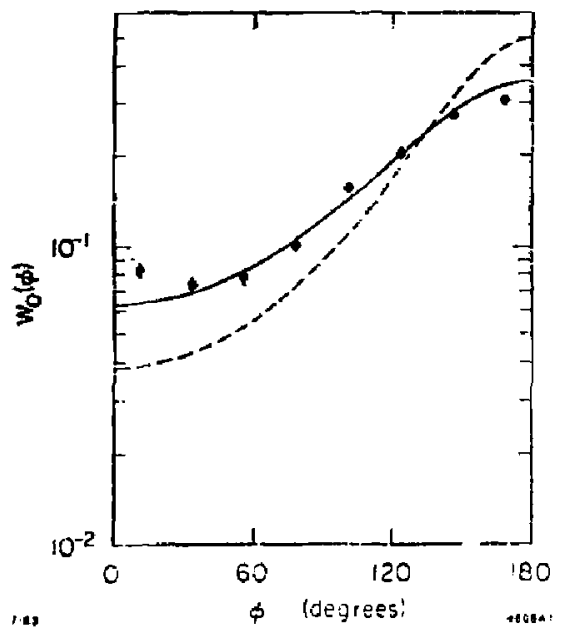

Fig. 1. $W_{0}(0)$ versus sollow. from Eq. (2) for $n_{\mathrm{max}}=20$, : ! ! ! lines: $a=\left(\sigma_{q} / \sigma_{1}\right)^{2}=1$, doti:i! lines: $\alpha=(0.35, j 0.5)^{2}$. Carlo result for IID $(\phi)$ for $\alpha=-1$ (resonance decay inclurich).

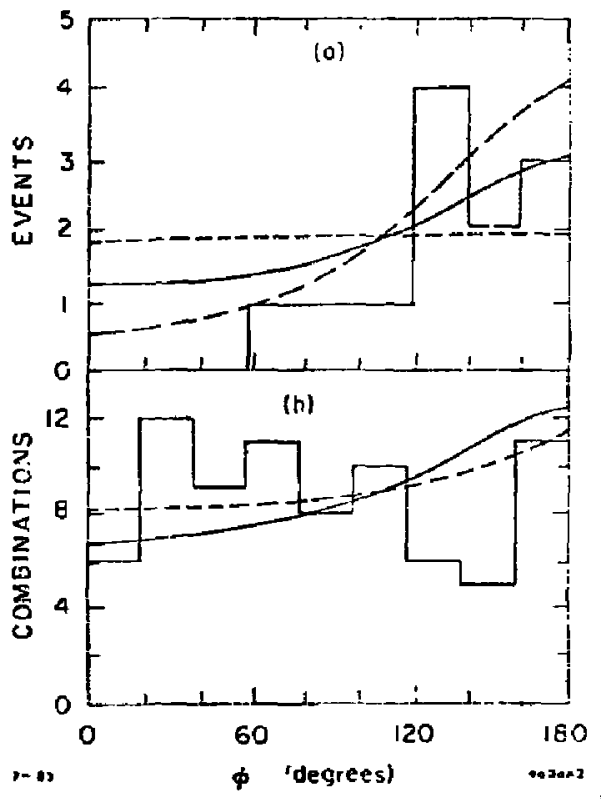

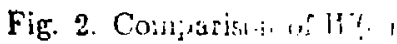
following [rom Eggs 11 ! : (2) $(a=1)$ wilh $a$. (a) Data from Ref. $\therefore,(\cdots \ldots)$ $p_{3}=0.5,(-\cdots), \cdots$ $(--) p_{3}=1$. (b) llata $1: 6$ Ref, 6 , solid line: $\because=:=:$ dashed line: predir!" : model of Rer. :. 
would be inclined to infer from this a large amount of diquark splitting, i.e. $0.5 \leqslant p_{3} \leqslant 1$. The TASSO group, however, has compared its results also with the prediction of the LUND model $\left.\right|^{3}$ which also gives a rather flat $\phi$ distribution for the $p-\tilde{p}$ pairs although in this model there is no diquark splitting at all (corresponding to $p_{3}=0$ in our notation). The reason for this behnvior ${ }^{8 !}$ lies in the manner gluon fragmentation is treated within the LUND model. In this model hadronization takes place along the color fux lines which will be distorted when a hard gluon is emitted. The Lorentz transformation necessary to go from the CMS of each string piece to the laboralory frame affects mostly the slow baryons. As the TASSO group applies a cut $|p| \leq 1.2 \mathrm{GeV} / \mathrm{c}$ to the $p$ and $p$ momenta, the correlation between the $p$ and the $\bar{p}$ becomes to a large extcol washed out ${ }^{8}$.

In order to study the nalure of the diquark by means of Eqs. (1) and (2) one, tharelore, needs baryon-antibaryou events in "thin" jets, i.e. quark jets which are not affected by gluon radiation. Kuowing more about baryon production in quark jets one could then again consider three-jet events, obtaining in this way more detajled information sbout fluon fragmentation. If in a good sample of clean two-jet events the o distribution of baryon-antibaryon pairs still turns out to be flat one might have to abandent the notion of the diquark at all.

\section{ACKNOWLEDGEMENTS}

1 would like to thank H. Frans, H. R. Gorbold, W. Majerotto, and in particular G. Rudolph for very helpful discussions and 11. R. Quinu for reading the manuscript. I am grateful to Professor S. D. Drell and the SLAC Tlrory Group for warm hospitality.

\section{REFERENCES}

1) G. Woir, taik at this Conference.

2) E. M. Ilgenfritz, J. Kripfganz and 1. Schiller, Acta ['lys. Polcoica !3!, 881 (1978); S. Ritter and J. Ranft, teta Phys. Polonica Bu11, 25? (1980).

3) B. Anderseob, G. Gustofecn and T. Sjöstrand, Nül. Phys, B1Eg, 45 (1982); B. Andersionn. G. Ciustafson, G. Ingtinann and $\boldsymbol{T}$. Sjüstrand, $\mathcal{Z}$. Phys. (13, 361 (145:-).

4) A. Bartl, H. Frazs and W. Majerot to, Phys. Rey. D20, 1061 (105: 
5] JADE Collaboration, W. Bartel et al., Phys. Lett. 104B, 325 (1021); and quoted by W. Koch, talk at 13th International Symposium on Winltiparticle Dynamics, Volendam, 1982, ed. W. Kittel, W. Melzger ant! A. Stergiou.

6) TASSO Collaboration, M. Althofl et al, Z. Phys. Ci7, 5 (1083).

7] A. Bartl, H. Fraas, H. R. Gerbold and W. Majerotto, Phys. Leit. 1.01\}, 427 . (1983).

8] G. Rudolph, private communication. 